\title{
Relationship between Brain Blood Flow and Carotid Arterial Flow in the Sheep Fetus
}

\author{
FRANK VAN BEL, CHRISTINE ROMAN, ROBERT J. M. KLAUTZ, DAVID F. TEITEL, AND \\ ABRAHAM M. RUDOLPH \\ Cardiovascular Research Institute, Deparment of Pediatrics, and Department of Obstetrics, Ginecology' and \\ Reproductive Sciences, University of California at San Francisco, San Francisco, California 94143
}

\begin{abstract}
The present study investigates whether changes in total brain blood flow can be reliably estimated by changes in carotid arterial blood flow in fetal and perinatal lambs. We therefore compared carotid arterial blood flow, measured with implanted transit-time ultrasound transducers, with brain blood flow, measured by radioactive microspheres in fetal lambs during normal oxygenation and during pulmonary ventilation with oxygen, with $\mathrm{PO}_{2}$ ranging from levels normal for the healthy fetus to levels normally seen postnatally. Cerebral perfusion pressure was modified over a wide range to alter brain blood flow: it was decreased by balloon occlusion of the brachiocephalic trunk and increased by a balloon occluder around the aortic isthmus. Carotid arterial blood flow and brain blood flow were closely related $(r=0.97, p<0.0001)$. The relationship was not altered at different levels of oxygenation. However, measurements during higher cerebral perfusion pressures, obtained during aortic isthmus occlusion, had a negative influence on the agreement between carotid arterial blood flow and brain blood flow. When excluding values obtained by aortic isthmus occlusion, changes of $20 \%$ or more in brain blood flow could be predicted with carotid arterial blood flow within a confidence limit of $95 \%$. Blood flow measurements in the carotid artery may be useful to estimate changes in brain perfusion. (Pediatr Res 35: 329-333, 1994)
\end{abstract}

\section{Abbreviations}

MCBP, mean carotid blood pressure

$\mathrm{Q}_{\text {brain, blood flow to brain }}$

Qextracerebrai, blood flow to skin of the head and skull

$Q_{\text {skin, }}$ blood flow to skin of the head

$Q_{\text {skull, }}$ blood flow to skull

$Q_{\text {car }}$, carotid arterial blood flow

ID, inner diameter

OD, outer diameter

The lamb fetus is frequently used in models to evaluate changes in antenatal and transitional $\mathrm{Q}_{\text {brain }}(1,2)$. Cerebral perfusion usually has been measured by repeated injections of radioactive microspheres (3-5). This method has the advantages of reliability and the ability to determine regional as well as total $\mathrm{Q}_{\text {brain. }}$ The main disadvantage is the limited number of blood flow measurements that can be performed. An increasing number of studies

Received April 27, 1993; accepted October 25, 1993.

Correspondence and reprint requests: Frank van Bel, M.D., University Hospital Leiden, Dept. of Pediatrics, Neonatal Unit, Building 35, P.O. Box 9600, 2300 RC Leiden, The Netherlands.

Supported by PHS Grant HL 35842. F. van Bel is a recipient of the Ter Meulenfund of the Netherlands Academy of Arts and Sciences. investigating the pattern of fetal and neonatal $Q_{\text {brain }}$ have used ultrasound-derived changes in the carotid artery as a measure of changes in $\mathrm{Q}_{\text {brain }}(6,7)$. Although regional $\mathrm{Q}_{\text {brain }}$ cannot be determined with this method, frequent estimations of $\mathrm{Q}_{\text {brain }}$ can be made. Moreover, in long-term experimental studies, changes in total $\mathrm{Q}_{\text {brain }}$ can be monitored with ultrasonic flow transducers around the carotid arteries. Also, in clinical studies, ultrasoundderived changes in arteries supplying the brain, such as the carotid artery, are used to investigate the relationship between brain perfusion and various antenatal and perinatal complications, such as growth retardation and perinatal asphyxia (8-10). However, until now, no studies were performed to validate the relationship between changes in total $Q_{\text {hrain }}$ and $Q_{\text {car. }}$.

We examined the relationship between changes in $\mathrm{Q}_{\mathrm{car}}$, measured with the transit-time ultrasound technique (11), and changes in radioactive microsphere-determined total $\mathrm{Q}_{\text {brain. }}$ We hypothesized that a close relationship and a good agreement existed between changes in flow measured by the two methods. This study was performed in fetal lambs before and during pulmonary ventilation and oxygenation to increase $\mathrm{PO}_{2}$ to levels seen postnatally. Changes in $Q_{\text {brain }}$ were induced by varying cerebral perfusion pressure over a wide range, including values well below and above the previously described limits of cerebral autoregulation $(12,13)$.

\section{MATERIALS AND METHODS}

Animals and surgical preparation. Before the initiation of these studies, all surgical and experimental procedures were approved by the Animal Care and Use Committee at the University of California, San Francisco. We studied 10 fetal sheep with gestational ages of $124-135 \mathrm{~d}$ and weights of $2550-4665 \mathrm{~g}$. The ewes were fasted for $24 \mathrm{~h}$ before surgery. After local anesthesia with $2 \%$ lidocaine, low epidural anesthesia was achieved with $4 \mathrm{~mL}$ of $1 \%$ tetracaine hydrochloride (Pontocaine $\mathrm{HCl}$; Breon Laboratories, New York, NY). Polyvinyl catheters (1.3 mm ID, 2.3 $\mathrm{mm}$ OD) were advanced from hind limb vessels into the ewe's descending aorta and inferior vena cava. $\mathrm{NaCl}(0.9 \%$ solution $)$ was infused continuously into the ewe, and 50-100 mg of ketamine hydrochloride (Vetalar; Parke-Davis, Morris Plains, NJ) was administered to the ewe as necessary to maintain sedation.

The pregnant horn of the uterus was exposed through a midline incision in the ewe's abdomen, and a uterine incision was made overlying the fetal hind limbs. Local anesthetic $(0.25 \%$ lidocaine hydrochloride) was administered before each fetal skin incision. Polyvinyl catheters $(0.75 \mathrm{~mm}$ ID, $1.2 \mathrm{~mm}$ OD) were placed in the fetal descending aorta and inferior vena cava via the hindlimb vessels. The fetal skin and uterine incisions were sutured. Through a thoracotomy in the third intercostal space, catheters were placed in the brachiocephalic trunk from the internal thoracic artery $(0.75 \mathrm{~mm}$ ID, $1.2 \mathrm{~mm}$ OD) and directly into the left atrium (20-gauge i.v. catheter, Becton Dickinson, Mountain View, CA) in those fetuses in which microsphere-determined 
Qbrain measurements were planned during pulmonary ventilation and oxygenation (described later). Then silicone rubber inflatable balloons were placed around the aortic isthmus and the brachiocephalic trunk. The fetal chest was sutured in layers. The fetal head and neck were exposed through the same uterine incision. A $3.5-\mathrm{mm}$ endotracheal tube was connected by an Y-tube to two $100-\mathrm{cm}$ lengths of flexible polyvinyl tubing $(3.2 \mathrm{~mm} \mathrm{ID,} 6.4 \mathrm{~mm}$ $\mathrm{OD})$. The tubing was filled with $0.9 \%$ saline, and the trachea was intubated. A second catheter was placed in the amniotic cavity and connected to the ventilation tubing to allow trachea fluid to flow to the amniotic cavity postoperatively. After exposing the carotid arteries in the neck, we placed appropriately sized transonic flow transducers (Transonic Systems, Inc., Ithaca, NY) around the carotid arteries to measure carotid blood flow $(\mathrm{mL} /$ $\mathrm{min}$ ). In four fetuses, a flow transducer was placed around both carotid arteries, and in the remaining six, only a single carotid artery was used for measuring carotid blood flow. The left forelimb was then exposed, and a polyvinyl catheter $(0.75 \mathrm{~mm}$ ID, $1.2 \mathrm{~mm}$ OD) was passed from the brachial artery to the brachiocephalic trunk, distal to the balloon occluder, to measure arterial blood pressure and for blood sampling. All incisions were sutured, the vascular catheters were filled with heparin sodium solution (1000 IU/mL) and sealed, and all catheters and ventilation tubing were exteriorized to the maternal flank and protected by a cloth pouch. Antibiotics $(400 \mathrm{mg}$ gentamicin, 1 million IU penicillin) were given into the amniotic cavity and maternal vein on the day of surgery and each day thereafter. The animals were allowed $24-48 \mathrm{~h}$ to recover from surgery. Earlier studies in our laboratory on lamb fetuses with comparable gestational age and surgery showed that this period was adequate for hemodynamic stabilization.

Physiologic measurements. Fetal blood pressures were monitored continuously with Statham P23D6 strain-gauge transducers, and Beckman R 612 (Beckman Instruments, Inc., Palo Alto, CA) or Gould 2800S (Gould, Inc., Cleveland, OH) polygraphs. Fetal carotid blood pressure was calculated with amniotic cavity pressure as zero reference. Fetal heart rate, measured by a cardiotachometer, which was triggered by an arterial pulse wave, was also measured continuously. Blood samples for determination of $\mathrm{pH}, \mathrm{PO}_{2}, \mathrm{PCO}_{2}$ (corrected for fetal temperature) and $\mathrm{Hb}$ (model 158 blood gas analyzer, Corning Medical, Medfield, MA; model OSM2 hemoximeter) were obtained from the carotid artery.

$\mathrm{Q}_{\mathrm{car}}$ was measured with the transit-time technique with ultrasonic flow transducers and ultrasonic transit-time blood flowmeter (Transonic Systems Inc.). The transonic flow transducer does not require close contact with the vessel. Reliable calibration and reproducibility have been shown in earlier studies $(11,14)$.

Blood flow to the head was measured with radionuclide-labeled microspheres as described previously (3). Microspheres, $15 \mu \mathrm{m}$ in diameter and labeled with ${ }^{114} \mathrm{In},{ }^{153} \mathrm{Gd},{ }^{57} \mathrm{Co},{ }^{51} \mathrm{Cr},{ }^{113} \mathrm{Sn},{ }^{85} \mathrm{Sr}$, ${ }^{95} \mathrm{Nb}$, or ${ }^{46} \mathrm{Sc}$ were injected into the fetal inferior vena cava during baseline conditions and into the left atrium during ventilation with oxygen over a 30 -s period while reference samples were obtained at a rate of $4 \mathrm{~mL} / \mathrm{min}$ from the brachiocephalic trunk for $1.00-1.25 \mathrm{~min}$. The microsphere injections were not associated with changes in heart rate or blood pressure. The volume of blood removed for analysis and for flow reference samples was replaced with an equal volume of a fetal donor or, in a minority of cases, with maternal blood. Blood to the head was determined as described previously in detail (3). Briefly, after completion of the study, the head was removed; separated into skin, skull, and brain tissue; weighed; and placed in formalin. The tissue was then carbonized in an oven at $350^{\circ} \mathrm{C}$, ground into a coarse powder, placed into plastic vials to a uniform height of $3 \mathrm{~cm}$, and counted in a 1000-channel multichannel pulse-height analyzer (Norland Corp., Fort Atkinson, WI). The activity of each isotope in the head was determined by the least-squares method as described previously (15). $\mathrm{Q}_{\text {skin }}, \mathrm{Q}_{\text {skull }}$, and $\mathrm{Q}_{\text {brain }}$ were calculated by comparing radioactivity of microspheres in the tissue with flow rate of the appropriate reference sample from the brachiocephalic trunk and expressed as $\mathrm{mL} / 100 \mathrm{~g} / \mathrm{min}$. Microsphere-determined cerebral blood flow was expressed in $\mathrm{mL} / \mathrm{min}$ to compare $Q_{\text {brain }}$ with $\mathrm{Q}_{\mathrm{car}}$.

The tubes connected to the endotracheal tube were opened and tracheal fluid was allowed to drain to provide ventilation to the fetus. These tubes were connected to a specially designed positive-pressure ventilator. On expiration, a solenoid in series with the expiratory tubing opened, and the expired air from the fetus was flushed from the tubing to the outside. This provided a small dead space for ventilation.

Experimental procedure. Ten fetuses were investigated during two conditions in a randomized order, with $(n=5)$ or without $(n=5)$ rhythmic pulmonary ventilation and oxygenation. The fetuses had ventilation with gases of various oxygen concentrations to achieve a range of arterial oxygen tensions. $\mathrm{PO}_{2}$ in the ventilated fetuses ranged from values normal for the healthy lamb fetus $(n=2)$ to values normal for the (preterm) newborn lamb $\left(n=3 ; \mathrm{PO}_{2}>6 \mathrm{kPa}\right)$. Surfactant (Exosurf, BurroughsWellcome Co., Research Park, NC) was instilled into the trachea before initiation of ventilation. Earlier studies in our laboratory have shown that changes in $Q_{\text {brain }}$, initiated by ventilation with oxygenation of the lamb fetus, are comparable to those occurring at birth (16).

After reaching a stable baseline level during each condition, carotid arterial pressure was decreased in steps of $5-10 \mathrm{~mm} \mathrm{Hg}$ by inflation of the brachiocephalic trunk balloon. At each step, when a steady state (heart rate, carotid blood pressure) had been reached, blood samples were taken, hemodynamic parameters and $\mathrm{Q}_{\text {car }}$ registered, and blood flow to the head measured by microspheres. We aimed to decrease the cerebral perfusion pressure well below the lower limit of cerebral autoregulation for the fetal lamb of the gestational age studied $(40-45 \mathrm{~mm} \mathrm{Hg})(12$, 13). The brachiocephalic balloon was then released, and after reaching steady state again, cerebral perfusion pressure was increased by steps of $10 \mathrm{~mm} \mathrm{Hg}$ by inflation of the aortic isthmus balloon until maximal inflation; all procedures were then repeated. Eight comparisons were made between $Q_{c a r}$ and $Q_{\text {brain }}$ in each fetus.

Statistical analysis. To investigate the relationship between $Q_{\text {brain }}$, determined by microspheres, and simultaneously determined $Q_{c a r}$, and the effect of oxygenation on this relationship, we used a multiple linear regression model with the following equation:

$$
\begin{aligned}
\mathrm{Y}=b_{0}+b_{\mathrm{Qbrain}} \mathrm{Qbrain}_{\text {bro }}+\mathrm{b}_{\mathrm{PO}_{2}} \mathrm{PO}_{2}+b_{\mathrm{Qbrain}} \times \mathrm{PO}_{2} \\
\cdot \mathrm{Q}_{\text {hrain }} \times \mathrm{PO}_{2}+\sum_{k=1}^{13} \mathrm{~b}_{\mathrm{l}_{\mathrm{k}}} \mathrm{L}_{\mathrm{k}}
\end{aligned}
$$

where $\mathrm{Y}$ is the dependent variable $\mathrm{Q}_{\mathrm{car}}$ and $\mathrm{b}_{0}$ its overall mean value. $Q_{\text {brain }}$ is the first independent variable, and its coefficient, $b_{Q_{b r a i n}}$, defines the slope of the $\mathrm{Q}_{c a r}-\mathrm{Q}_{\text {brain }}$ relationship. The second $\left(\mathrm{PO}_{2}\right)$ and third $\left(\mathrm{Q}_{\text {brain }} \times \mathrm{PO}_{2}\right)$ independent variables are action variables, whose coefficients, $\mathrm{b}_{\mathrm{PO}_{2}}$ and $\mathrm{b}_{\mathrm{Qbrain}} \times \mathrm{PO}_{2}$, indicate the independent effect of $\mathrm{PO}_{2}$ on $\mathrm{Q}_{\text {car }}$ (affecting the intercept of the $Q_{c a r}-Q_{\text {brain }}$ relationship) and the interactive effect of $\mathrm{PO}_{2}$ and $Q_{\text {brain }}$ on $\mathrm{Q}_{\mathrm{car}}$ (indicating the effect of ventilation and oxygenation on the slope of the $Q_{c a r}-Q_{b r a i n}$ relationship), respectively. Finally, to correct for interanimal variability, 13 dummy variables $\left(D_{1}-D_{13}\right)$ were introduced for the 14 brain halves (see also Results) in 10 animals and included in this analysis (17). To determine the statistical significance of any variable, an $F$ test was performed by dividing the mean square of that variable by the mean square residual.

To assess the agreement between $Q_{\text {brain }}$ and $Q_{\text {car }}$ as indicators for changes in cerebral perfusion, we used the method described by Bland and Altman (18). This method calculates the mean difference (d) between both measurements and the SD of the differences (s). From these data, the limits of agreement $(d \pm 2 s)$ can be estimated. We therefore normalized the data per animal; 
Table 1. MCBP, pH and arterial blood gases, and radioactive microsphere-determined blood flow (in $\mathrm{mL} / \mathrm{min}$ ) to $Q_{\text {extracerebral }}$ and $Q_{\text {hrain }}$ at lowest, baseline, and highest MCBP values*

\begin{tabular}{lccc}
\hline & Lowest MCBP & Baseline MCBP & Highest MCBP \\
\hline Fetuses without ventilation & & & $81 \pm 8 \ddagger$ \\
$\mathrm{MCBP}(\mathrm{mm} \mathrm{Hg})$ & $19 \pm 7$ & $52 \pm 13 \dagger$ & $7.38 \pm 0.04$ \\
$\mathrm{pH}$ & $7.36 \pm 0.04$ & $7.36 \pm 0.02$ & $7.3 \pm 0.5$ \\
$\mathrm{PCO}_{2}(\mathrm{kPa})$ & $7.6 \pm 0.9$ & $7.7 \pm 0.7$ & $3.2(1.9-3.3)$ \\
$\mathrm{PO}_{2}(\mathrm{kPa}) \S$ & $3.1(1.7-3.3)$ & $3.1(1.9-3.5)$ & $84 \pm .12(47 \pm 27)$ \\
$\mathrm{Q}_{\text {extracerebral }}$ & $17 \pm 15(12 \pm 10)$ & $65 \pm 39(40 \pm 21)$ & $58 \pm 21(120 \pm 54) \dagger$ \\
$\mathrm{Q}_{\text {brain }}$ & $12 \pm 4(14 \pm 9)$ & $49 \pm 25(102 \pm 59) \dagger$ & 41 \\
\% of $\mathrm{Qbrain}_{\text {of total flow }}$ & 41 & 43 & $78 \pm 12 \ddagger$ \\
$\mathrm{MCBP}(\mathrm{mm} \mathrm{Hg})$ & & $53 \pm 10 \dagger$ & $7.43 \pm 0.04$ \\
$\mathrm{pH}$ & $7.40 \pm 0.07$ & $7.40 \pm 0.07$ & $6.4 \pm 1.1$ \\
$\mathrm{PCO}(\mathrm{kPa})$ & $6.0 \pm 2.0$ & $6.4 \pm 0.6$ & $5.9(2.3-24.5)$ \\
$\mathrm{PO}(\mathrm{kPa}) \S$ & $11.7(2.4-20)$ & $7.7(2.5-8.7)$ & $49 \pm 19(32 \pm 12)$ \\
$\mathrm{Q}_{\text {extracerebral }}$ & $15 \pm 5(10 \pm 5)$ & $41 \pm 18(26 \pm 9)$ & $44 \pm 15(89 \pm 32) \dagger$ \\
$\mathrm{Q}_{\text {rrain }}$ of $\mathrm{Q}_{\text {brain }}$ of total flow & $13 \pm 3(23 \pm 5)$ & $31 \pm 9(56 \pm 16) \dagger$ & 47 \\
\hline
\end{tabular}

*Values are means $\pm 1 \mathrm{SD}$. Numbers in parentheses represent $\mathrm{Q}_{\text {extracerebral }}$ and $\mathrm{Q}_{\text {brain }}$ expressed as $\mathrm{mL} / 100 \mathrm{~g} / \mathrm{min}$ (means $\pm 1 \mathrm{SD}$ ).

$\dagger p<0.05$ vs low MCBP.

$\ddagger p<0.05$ vs low and baseline MCBP.

$\S$ Because oxygenation of fetuses with ventilation ranged from $\mathrm{PO}_{2}$ values normal for the fetus to those normal for newborn lamb, the median and range for this variable has been given.

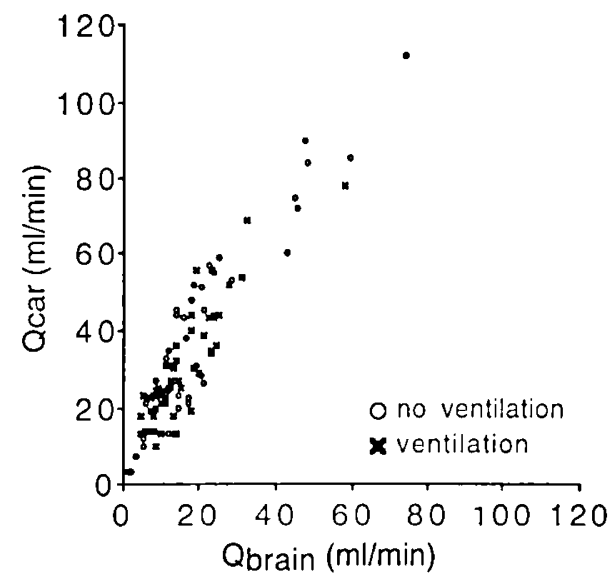

Fig. 1. Individual values of $\mathrm{Q}_{\mathrm{car}}$ as a function of ipsilateral radioactive microsphere-determined $\mathrm{Q}_{\text {brain }}(n=14)$.

values of $Q_{c a r}$ and $Q_{\text {brain }}$ during baseline level were considered to be $100 \%$, whereas the other values were expressed as the percentage change from these baseline values.

Differences of blood gases, $\mathrm{pH}, \mathrm{MCBP}, \mathrm{Q}_{\text {brain }}$, and $\mathrm{Q}_{\text {extracerebral }}$ between lamb fetuses without ventilation and with ventilation/ oxygenation were compared with the $t$ test. Differences of these variables among baseline, lowest, and highest MCBP values were compared by one-factor analysis of variance for repeated measurements, followed by the Newman-Keuls test when a significant difference was found. Statistical significance was assumed as $p<$ 0.05 .

\section{RESULTS}

No differences were found for $\mathrm{PCO}_{2}, \mathrm{pH}, \mathrm{Hb}$, or heart rate between the fetuses without ventilation or with ventilation/ oxygenation at any MCBP level or among baseline, highest, and lowest $\mathrm{MCBP}$ values. Median $\mathrm{PO}_{2}$ values in the fetuses with ventilation were higher than in those without ventilation. Table 1 summarizes these data. This table also shows microspheredetermined $\mathrm{Q}_{\text {extracerebral }}\left(\mathrm{Q}_{\text {skin }}\right.$ and $\left.\mathrm{Q}_{\text {skull }}\right)$ and $\mathrm{Q}_{\text {brain }}$ in the fetuses without ventilation and with ventilation/oxygenation at the different cerebral perfusion pressures. No significant difference was seen in the relationship between $Q_{\text {extracerebral }}$ and $Q_{\text {brain }}$ among the different levels of perfusion pressure. The amount of blood perfusing the brain was always $41-47 \%$ of the total amount of blood flowing to the head regardless of cerebral perfusion pressures and whether the fetus had ventilation. Blood flow to the

Table 2. Results of multiple linear regression analysis of $Q_{c a r}$ dependent variable on three independent variables*

\begin{tabular}{lccrcc}
\hline $\begin{array}{c}\text { Independent } \\
\text { variables }\end{array}$ & Coefficient & SEM & SC & $t$ value & $p$ value \\
\hline Intercept & 8.07 & 2.93 & 8.07 & 2.76 & 0.01 \\
$\mathrm{Q}_{\text {brain }}$ & 1.43 & 0.12 & 0.89 & 12.17 & $<0.0001$ \\
$\mathrm{PO}_{2}$ & -0.003 & 0.06 & -0.01 & -0.06 & 0.95 \\
$\mathrm{PO}_{2} \times \mathrm{Q}_{\text {brain }}$ & 0.001 & 0.002 & 0.06 & & 0.61 \\
ANOVA table & $d f$ & $\mathrm{SS}$ & $\mathrm{MS}$ & $F$ value & $p$ value \\
\hline Regression & 16 & 37171.19 & 2323.20 & 53.92 & $<0.0001$ \\
Residuals & 80 & 3447.03 & 43.09 & & \\
Total & 96 & 40618.23 & & & \\
\hline
\end{tabular}

* The three independent variables were microsphere-determined $\mathrm{Q}_{\mathrm{brain}}, \mathrm{PO}_{2}$ (whose coefficient bPO2 indicate the independent effect of this variable on $\mathrm{Q}_{\mathrm{car}}$ ), and the interaction variable $\mathrm{PO}_{2} \times \mathrm{Q}_{\text {brain }}$ (whose coefficient $\mathrm{b}_{\mathrm{PO}_{2}} \times \mathrm{Q}_{\mathrm{brain}}$ indicate the interactive effect of this variable on the slope of the $\mathrm{Q}_{\mathrm{car}}-\mathrm{Q}_{\mathrm{brain}}$ relationship); $\mathrm{b}_{0}$ is the overall intercept. Animal variability was included in the model by introducing dummy variables, coded by effects, for the 14 brain-halves in 10 animals. The regression equation was statistically significant $(r=0.97, p<0.0001)$. SC, standard coefficient; ANOVA, analysis of variance; SS, sum of squares; MS, mean square. 


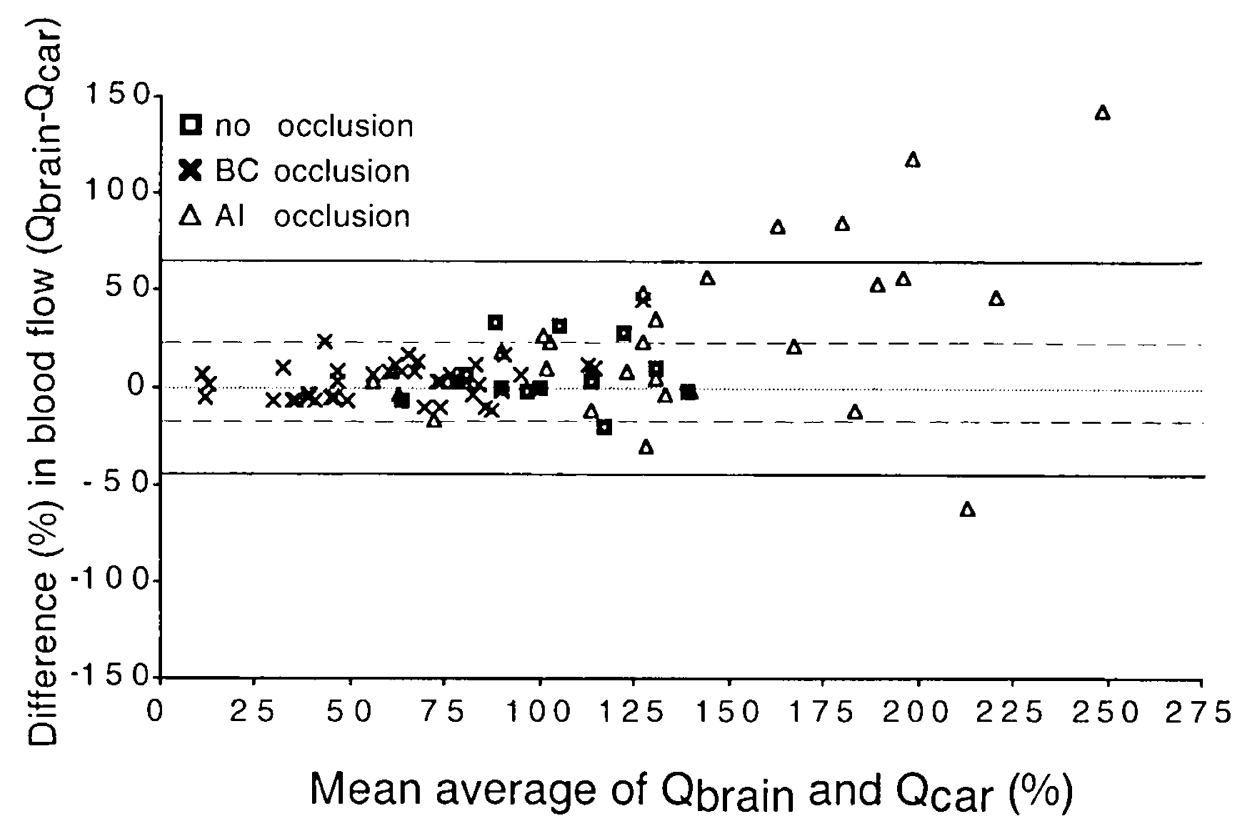

Fig. 2. Difference in changes (\%) between $\mathrm{Q}_{\mathrm{car}}$ and ipsilateral radioactive microsphere-determined $\mathrm{Q}_{\mathrm{brain}}$ as a function of the mean average of $\mathrm{Q}_{\mathrm{car}}$ and $\mathrm{Q}_{\mathrm{brain}}$. The two solid horizontal lines indicate the lower and upper limit of agreement $(\mathrm{d} \pm 2 \mathrm{~s})$ when all measurements are included; the two hatched horizontal lines indicate the lower and upper limit of agreement without the measurements made after inflation of the aortic isthmus balloon. $B C$, Brachiocephalic; AI, aortic isthmus.

brain in relation to tissue weight was much higher than to extracerebral tissue. Ventilation and oxygenation tended to decrease cerebral and extracerebral blood flow, but these decreases were not significant. During baseline and highest arterial pressures, blood flow to extracerebral and cerebral tissue was significantly higher as compared with lowest carotid pressures.

In the four fetuses in which blood flow was measured in both carotid arteries, left and right $\mathrm{Q}_{\text {car }}$ was not significantly different (mean $\pm 1 \mathrm{SD}$; left carotid artery, $43 \pm 17 \mathrm{~mL} / \mathrm{min}$; right carotid artery, $46 \pm 18 \mathrm{~mL} / \mathrm{min}$ ). A close relationship was found in the fetuses between left and right carotid blood flow with a slope of the regression line close to $1(r=0.89, p<0.001, y=0.92 x+$ 8.26).

Because blood flow was not measured in both carotid arteries in all fetuses, we divided the brain into left and right halves and compared $\mathrm{Q}_{\mathrm{car}}$ with $\mathrm{Q}_{\text {brain }}$ (expressed as absolute flow, $\mathrm{mL} / \mathrm{min}$ ) in the ipsilateral halves of the brain. In this manner we compared 14 brain halves with the blood flow in 14 ipsilateral carotid arteries. Figure 1 shows the relationship between $\mathrm{Q}_{\mathrm{car}}$ and the hemicerebral flow $(r=0.92, p<0.001, y=1.49 x+7.82)$. The multiple linear regression model, as described in Material and Methods, investigated the effects of oxygenation on the relationship and incorporated the animal variability. Table 2 shows the results: oxygenation had no effect on the intercept or the slope of the regression line of this relationship, whereas animal variability was not significant. Analysis of residuals reveiled a homogeneous distribution of the residuals versus either the fitted or the dependent variable (Table 2). Using the same multiple linear regression model, we found a similar close relationship between left or right $\mathrm{Q}_{\mathrm{car}}$ and total $\mathrm{Q}_{\mathrm{brain}}(r=0.94, p<0.0001$; the coefficient $b_{\text {Qcar }}$ was 0.85 ). Also, oxygenation here had no effect on intercept or slope of the regression line of the relationship. In this analysis nine dummy variables $\left(D_{1}-D_{9}\right)$ were introduced for the 10 animals to correct for interanimal variability.

For several reasons, thoroughly discussed by Bland and Altman (18), correlation between two methods does not give us information about the error with which one can predict one measurement given the other. Therefore, we assessed the agreement between $Q_{\text {car }}$ and $Q_{\text {brain }}$, which is shown in Figure 2. Taking all values into account, we found that agreement was poor; limits of agreement $(\mathrm{d} \pm 2 \mathrm{~s})$ ranged from $-44 \%$ to $+64 \%$. However, when values obtained by aortic isthmus occlusion were excluded, the agreement improved considerably, with limits of agreement ranging from $-19 \%$ to $+25 \%$ (Fig. 2; hatched horizontal lines).

\section{DISCUSSION}

The present study in the fetal lamb shows a close relationship between changes in radioactive microsphere-determined total $\mathrm{Q}_{\text {brain }}$ and changes in $\mathrm{Q}_{\mathrm{car}}$. Oxygenation of the lamb fetus to levels normally seen in the newborn lamb did not alter this relationship. Of importance to potential clinical application is the fact that the proportion of total blood flow to the head that was directed to the brain tissue was similar over a wide range of cerebral perfusion pressures, including values well below and above the estimated limits of cerebral autoregulation. This situation was true for lamb fetuses without ventilation and those with ventilation $(41-43 \%$ and $43-47 \%$, respectively). In this respect it is important to state, however, that we investigated only healthy sheep. In case of brain injury (e.g. brain edema), the proportion between extracranial and intracranial blood flow may be changed. The agreement between both measurements, excluding values obtained during aortic isthmus occlusion, indicates that changes in $\mathrm{Q}_{\text {brain }}$ of $20 \%$ or more could be predicted from changes in $Q_{\text {car }}$ within the $95 \%$ confidence interval in the lamb during fetal and transitional periods. This provides the advantages of monitoring brain perfusion continuously rather than intermittently, as with radioactive microspheres, as well as the ability to observe changes in brain perfusion as a function of time. If this relationship in the lamb were applied to the human fetus and infant, it would provide an opportunity to assess changes in $Q_{b r a i n}$ by measuring $\mathrm{Q}_{\mathrm{car}}$ with noninvasive techniques. Although different in some respects, blood supply to the brain in both the lamb and the human fetus and newborn is predominantly provided by the carotid arteries (19-21). In the sheep, the carotid arteries predominantly supply the brain via the carotid rete, from which a short large vessel supplies all the blood to the circle of Willis, whereas the vertebral-basilar vascular system has no role or only a minor one $(19,20)$. Indeed, occlusion of both carotid arteries in the sheep has been shown to cause virtually complete ischemia with loss of electrical cortical activity in about $8 \mathrm{~s}(20)$. Eighty to $90 \%$ of the blood flow to the human brain is normally supplied 
by the carotid arteries (22). In adults, Risberg et al. (21) showed a significant relationship between Doppler ultrasound-measured common $Q_{\text {car }}$ velocity and ${ }^{133}$ Xenon inhalation-measured $Q_{\text {brain }}$. In our study, actual $\mathrm{Q}_{\mathrm{car}}$ was measured. Doppler ultrasonography, mostly used in the clinical studies, measures blood flow velocity and not absolute flow. To calculate absolute flow, it is necessary to measure the cross-sectional area of the vessel and the average blood flow velocity. Velocity is related to absolute flow if the internal diameter of the vessel does not change. Although major changes in diameter of carotid arteries do not usually occur, there are small changes during the cardiac cycle and during changes of cerebral perfusion pressure (23-25). Moreover, Sonesson and Herin (26) clearly showed that Doppler-measured blood flow velocity in large intracranial arteries in newborn lambs underestimated changes in actual $\mathrm{Q}_{\text {brain }}$ induced by changes in arterial carbon dioxide tension, probably because of a concomitant change in internal diameter of the arteries under investigation.

The reason for the relatively poor agreement between $\mathrm{Q}_{\mathrm{car}}$ and $Q_{\text {brain }}$ when measurements obtained during aortic isthmus occlusion are included is not apparent. A possible explanation is that at higher cerebral perfusion pressures, collaterals between vertebral and ventral spinal arteries may be recruited. These collaterals may become important shunts for the cerebral blood supply via the normal small basilar artery, which normally does not contribute to the blood supply of the circle of Willis $(19,20)$.

In conclusion, transit-time ultrasound-monitored $\mathrm{Q}_{\mathrm{car}}(\mathrm{mL} /$ $\mathrm{min}$ ) shows a close linear relationship with radioactive microsphere-determined blood flow to the brain in the fetal lamb. This relationship is not altered by pulmonary ventilation and oxygenation of the fetus. The assessment of agreement showed that changes in $Q_{\text {brain }}$ larger than $20 \%$ can be monitored by this method, although aortic balloon occlusion-induced higher cerebral perfusion pressures have a negative influence on the agreement between $Q_{c a r}$ and actual $Q_{\text {brain }}$.

\section{REFERENCES}

1. Rudolph AM, Heymann MA 1967 The circulation of the fetus in utero Methods for studying distribution of blood flow, cardiac output and organ blood flow. Circ Res 21:163-184

2. Papile L, Rudolph AM, Heymann MA 1985 Autoregulation of cerebral blood flow in the preterm fetal lamb. Pediatr Res 19:159-161

3. Heymann MA, Payne BD, Hoffman JIE, Rudolph AM 1977 Blood flow measurements with radionuclide-labeled particles. Prog Cardiovasc Dis 20:55-79

4. Thiringer K, Hrbek A, Karlsson K, Rosen KG, Kjellmer 11987 Postasphyxial cerebral survival in newborn sheep after treatment with oxygen free radical scavengers and a calcium antagonist. Pediatr Res 22:62-66

5. Rosenberg AA, Murdaugh E, White CW 1989 The role of oxygen free radicals in postasphyxia cerebral hypoperfusion in newborn lambs. Pediatr Res 26:215-219

6. Wladimiroff J, Tonge H, Stewart $P 1986$ Doppler ultrasound assessment of cerebral blood flow in the human fetus. Br J Obstet Gynaecol 93:93-99

7. van Bel F, Klautz RJM, Schipper IB, Teitel DF, Baan J 1993 Auto-regulatory ability of cerebral circulation before and after indomethacin in the newborn lamb. Pediatr Res 34:178-181

8. Wladimiroff JW, van de Wijngaard JAGW, Degami S, Noordam MJ, van de Eyck J, Jonge MM 1987 Cerebral and umbilical arterial blood flow velocity wave form in normal and growth-retarded pregnancies. Obstet Gynecol 69:705-709

9. Lingman G, Marsal K 1989 Noninvasive assessment of cranial blood circulation in the fetus. Biol Neonate 56:129-135

10. van Bel F, Van de Bor M, Stijnen T, Baan J, Ruys JH 1987 Cerebral blood flow velocity pattern in healthy and asphyxiated newborns: a controlled study. Eur J Pediatr 146:461-467

11. Dobson AD, Sellers AF, McLeod FD 1986 Performance of a cuff-type blood flowmeter in vivo. J Appl Physiol 21:1642-1648

12. Szymonowicz W, Walker AM, Yu VY. Stewart ML, Cannata J, Cussen L 1990 Regional cerebral blood flow after hemorrhagic hypotension in the preterm. near-term, and newborn lamb. Pediatr Res 28:361-366

13. Purves MJ, James IM 1969 Observations on the control of cerebral blood flow in the sheep fetus and newborn lamb. Circ Res 25:651-667

14. Hartman J, Koernier J, Lancaster L. Gorczynski R 1985 In vivo calibration of a transit-time ultrasound system for measuring ascending aorta volume flow. Pharmacologist 27:127-132

15. Baer RW, Payne BA, Verrier ED, Vlahakes GJ. Molodowitch D. Uhlig PN, Hoffman JIE 1984 Increased number of myocardial blood flow measurements with radionuclide-labeled microspheres. Am J Physiol 246:H418$\mathrm{H} 434$

16. Iwamoto HS, Teitel DF, Rudolph AM 1987 Effect of birth-related events on blood flow distribution. Pediatr Res 22:634-640

17. Slinker BK, Glantz SA 1990 Missing data in two-way analysis of variance. Am J Physiol 258:R291-R297

18. Bland JM, Altman DG 1986 Statistical methods for assessing agreement between two methods of clinical measurement. Lancet 1:307-310

19. Baldwin BA, Bell FR 1963 Blood flow in the carotid and vertebral arteries of the sheep and calf. J Physiol (Lond) 167:448-462

20. May NDS 1977 The Anatomy of the Sheep: A Dissection Manual, 3rd Ed. University of Queensland Press, Queensland, Australia, pp 237-240

21. Risberg J, Smith P 1980 Prediction of hemispheric blood flow from carotid velocity measurements: a study with the Doppler and ${ }^{133}$ Xenon inhalation techniques. Stroke 11:399-402

22. Roberts B, Hardesty WH, Holling MC, Reivich M, Toole JF 1964 Studies on extracranial cerebral blood flow. Surgery 56:826-839

23. Kontos HA, Wei EP, Navari RM 1978 Responses of cerebral arteries and arterioles to acute hypotension and hypertension. Am J Physiol 234:H371H378

24. Ulmatsu S, Yang A, Preziosi TJ 1983 Measurement of carotid blood flow in man and its application. Stroke 14:256-262

25. Faraci FM, Heistad DD 1990 Regulation of large cerebral arteries and cerebral microvascular pressure. Circ Res 66:8-17

26. Sonesson SF, Herin P 1988 Intracranial arterial blood flow velocity and brain blood flow during hypocarbia and hypercarbia in newborn lambs: a validation of range-gated Doppler ultrasound flow velocimetry. Pediatr Res 24:423-426 